\title{
ETNICIDAD Y ARQUEOLOGÍA: TRAS LA IDENTIDAD DE LOS VETTONES
}

\section{ETHNICITY AND ARCHAEOLOGY: AFTER THE IDENTITY OF THE VETTONS}

\author{
por
}

GONZALO RUIZ ZAPATERO Y

JESÚS R. ÁLVAREZ-SANCHÍS *

RESUMEN La configuración de grupos étnicos en la Edad del Hierro es un fenómeno que empieza a ser conocido y la posibilidad de estudiar sus correlatos materiales constituye una línea de investigación difícil pero muy sugestiva. La exploración de las relaciones entre la etnicidad y sus posibles indicadores arqueológicos se realiza sobre los Vettones, uno de los más importantes pueblos prerromanos del Occidente de la Meseta. Para ello se estudian dos elementos fundamentales: los famosos verracos y las cerámicas con decoración a peine, que debieron actuar como elementos delimitadores de identidad étnica. Se argumenta que esta línea de análisis puede ofrecer interesantes perspectivas sobre el proceso de etnogénesis de los Vettones y su implantación territorial.

\begin{abstract}
The emergence of ethnic groups during the Iron Age is a process which begins to be known. The potential of material culture as an indicator of ethnic identity constitutes a difficult avenue of research, but one with future. The exploration of relationships between ethnicity and material culture is considered for the Vettones, one of the most famous prerroman people in Western Iberia. The study analyses two basic elements, zoomorphic stone sculptures and combed pottery, and shows how both were probably used as markers of ethnic identity. It is argued that this approach offers interesting insights into the emergence of the Vettones and their territorial setting.
\end{abstract}

Palabras claves Arqueología. Identidad étnica. Edad del Hierro. Vettones. Meseta. Verracos. Cerámica a peine. Fronteras.

Key words Archaeology. Identity. Vettones. Meseta. Zoomorphic stone sculptures. Combed pottery. Frontiers.

* Departamento de Prehistoria, Universidad Complutense. 
La Arqueología de las primeras décadas del siglo XX estableció una ecuación simple y simplista entre "pueblo"-"lengua" y "cultura arqueológica" que ha perdurado largo tiempo, y en algunos casos aún permanece (Jones 1997). Esta aproximación, que fue bien formulada en su tiempo por V.G. Childe, ha sido ampliamente utilizada en la Arqueología europea (Veit 1989), y tan sólo desde hace 10-15 años ha sido cuestionada a fondo (Renfrew 1987; Graves-Brown et al. 1996). Como resultado de esa crítica y del interés suscitado por los antropólogos sobre el concepto de etnicidad (Barth 1969; Dragadze 1980 y Banks 1996), los propios arqueólogos han empezado a ocuparse de la etnicidad en el pasado y cómo estudiarla desde una perspectiva estrictamente arqueológica (Olsen y Kobylinski 1991; Renfrew 1993; Shennan 1989 y 1991) así como de los procesos de etnogénesis (Dolukhanov 1989). En los últimos años han aparecido varias síntesis valiosas, como la monografía de la británica S. Jones (1997), que hace una revisión historiográfica del estudio de la etnicidad en Arqueología y ofrece interesantes propuestas teórico-metodológicas, o la del estadounidense J.M. Hall (1997) sobre la identidad étnica en la Antigua Grecia, que ha merecido un buen conjunto de comentarios críticos en las páginas del Cambridge Archaeological Journal (Jones 1998; Just 1998 y Renfrew 1998), y finalmente las de S. James (1999) sobre la etnicidad celta y la de P. Wells (2001) sobre la identidad y las gentes de la Edad del Hierro europea. Por otro lado se han realizado las primeras recopilaciones bibliográficas sobre etnicidad y arqueología (Emberling 1997). A todo ello no es ajeno en absoluto la importancia que las etnias y los nacionalismos excluyentes están adquiriendo a finales del siglo XX, especialmente en Europa (Eriksen 1993).

En la arqueología española han aparecido en los últimos años varios estudios importantes que abordan el tema de la etnicidad en el registro arqueológico, considerando el caso de los Celtíberos (Burillo 1998) y el de los Iberos (Ruiz y Molinos 1993). A pesar de que sobre el último caso se hayan manifestado algunos reparos y precauciones (Díaz-Andreu 1998), que no afectan a la calidad de la propuesta original. Pero es cierto que la aproximación tradicional, iniciada con los trabajos de Bosch Gimpera, se interesaba por la delimitación de las áreas tribales o de populi a partir de la información contenida en las fuentes clásicas y no se planteaba el contenido real de la etnicidad de los grupos prerromanos. En otras palabras, se intentaba un acercamiento al ethnos según la interpretatio de los autores clásicos, pero se ignoraba por completo qué era y cómo se podía estudiar la etnicidad.

Aquí queremos proponer la posibilidad de realizar una aproximación a la etnicidad pretérita desde presupuestos arqueológicos. Somos muy conscientes de los problemas y limitaciones que tal empeño conlleva, pero al mismo tiempo tenemos la convicción de que la apertura de una línea de investigación en este sentido tiene grandes perspectivas de futuro. Aunque para avanzar tengamos que construir toda una metodología arqueológica que lo permita; construcción de teoría y metodología que como hemos visto más arriba ya se ha iniciado. Pero antes de nada debemos comenzar por considerar algunas cuestiones teóricas previas. Primero, ¿Cómo podemos definir la etnicidad ?, segundo ¿Qué implicaciones tiene la definición antropológica para un estudio arqueológico de la misma?, y tercero ¿Qué relaciones -si es que las hay- existen entre la etnicidad y la cultura material?. Después analizaremos el caso del grupo arqueológico vettón en las penillanuras occidentales de la Meseta, entre el Tajo y el Duero. La aproximación a la etnicidad vettona la realizamos básicamente a partir de lo que consideramos indicadores simbólicos étnicos: en primer lugar las esculturas zoomorfas en piedra-los famosos verracos-y en segundo lugar las cerámicas con decoración a peine. Para terminar, haremos unas reflexiones sobre las posibles vías de investigación futura que abre esta exploración de la etnicidad vettona a través de la cultura material. 


\section{¿QUÉ ES LA ETNICIDAD?}

Shennan (1989), en una de las primeras aproximaciones arqueológicas a la etnicidad, la definió como "la identificación auto-consciente con un grupo determinado, basada, al menos en parte, en un área específica u origen común". Estableció así lo que en nuestra opinión son los tres rasgos básicos de cualquier definición de etnicidad: primero, la propia percepción del grupo que en definitiva es lo que genera el sentido de identidad; segundo, la delimitación del territorio ocupado: el territorio del grupo étnico, y tercero, la asunción cierta o inventada de una continuidad a partir de unos ancestros comunes.

Desde esa definición se ha planteado que los criterios más universales de configuración de la etnicidad tienen un fuerte componente subjetivo, así Hall (1998:266) considera que básicamente son dos: la reclamación explícita de una relación de parentesco y la conciencia de compartir una misma historia, lo que está invariablemente asociado a un territorio concreto actual, anterior o imaginado (territorio primordial). Se afirma así que los grupos étnicos construyen su identidad discursivamente, en opinión de Hall (1998: 267) lo que dicen/dijeron sobre sí mismos es/fue más importante que lo que hacen/hicieron en cualquier sentido objetivo. Este planteamiento defiende que la etnicidad es, por encima de todo, una cuestión de lo que la gente dice y ello, como veremos más adelante, tiene profundas implicaciones para la arqueología.

La mejor conceptualización de etnicidad es, en nuestra opinión, la de S. Jones (1997: xiii). Define como identidad étnica "aquel aspecto de la auto-conceptualización personal que resulta de la identificación con un grupo más amplio por oposición a otros sobre la base de una diferenciación cultural percibida y/o una descendencia común". Mientras que un grupo étnico sería "cualquier grupo de gente que se considera así mismo apartado de otros y/o es apartado por otros con los que interactúa o coexiste sobre la base de sus percepciones de diferenciación cultural y/o descendencia común". Finalmente, para esta autora la etnicidad serían "todos aquellos fenómenos sociales y psicológicos asociados con una identidad de grupo culturalmente construida. El concepto de etnicidad se centra en las maneras por las que los procesos sociales y culturales se cruzan unos con otros en la identificación de grupos étnicos y la interacción entre ellos" (Jones 1997: xiii). De todo lo anterior se deduce que la etnicidad es una categoría histórica que se define en el proceso histórico; la etnicidad no es estática, es algo vivo, constantemente reafirmado y puesto al día. Sus raíces no están en una esencia inmutable o un "espíritu" místico, sino en el seno de las propias prácticas sociales de los grupos humanos, a través de las cuales se constituye la sociedad. Esto ayuda a entender la desconcertante complejidad de la etnicidad, su mutabilidad y su carácter elusivo (James 1999: 68).

Las características más importantes de la etnicidad en la investigación contemporánea han sido resumidas recientemente por Simon James (1999: 76-77):

(a) es un constructo moderno, que puede haber tenido poco que ver con la historia "real" de los individuos/grupos. Vista desde dentro la etnicidad es lo que la gente cree sobre su identidad y las ideas que tiene sobre su origen, (b) no es una cosa estática que se posee, sino un complejo proceso histórico social, (c) la gente puede no tener ningún tipo de identidad étnica, la identidad étnica sólo puede surgir por oposición a otras identidades étnicas, (d) las identidades étnicas son más diferencias percibidas de los otros que similitudes, (d) las identidades étnicas pueden ser múltiples; además de género, religión, puede haber más de una identidad étnica, (e) una identidad étnica dentro del grupo puede ser más importante para unos que para otros, (f) las identidades étnicas son escasamente homogéneas y pueden tener una gran complejidad interna, $(\mathrm{g})$ la aparente similitud cultural no es un indicador seguro de etnicidad compartida, (h) las identidades étnicas difícilmente se encuentran nítidamente delimitadas, (i) las identidades étnicas son fluidas y situacionales; no se expresan durante todo el tiempo, (j) las identidades étnicas están continuamente cambiando, (k) los símbolos de etnicidad no están fijados en naturaleza o valor, (l) los grupos étnicos comúnmente basan su legitimidad a través de la reclamación de profundas raíces históricas, y $(\mathrm{m})$ el desarrollo de cada etnicidad depende de circunstancias históricas específicas. 
En resumen, la etnicidad hoy, aunque puede estar basada en parte en elementos heredados, como la lengua, la religión, la descendencia y un área de origen, es considerada como un tema de auto-reconocimiento de grupo, de auto-identidad y por lo tanto es vista como un constructo moderno (Renfrew 1998: 275). En fin, es una categoría de clasificación social que es deliberadamente construida, dicursiva y autoconsciente por parte de los grupos sociales, más que esencialista, innata, congénita o ligada a nociones de raza (Morris 1998: 273). La etnicidad es, en gran medida, algo nuevo que precisa ser pensado y analizado desde perspectivas históricas, antropológicas y arqueológicas.

\section{LA ETNICIDAD DESDE UNA PERSPECTIVA ARQUEOLÓGICA}

De las definiciones ofrecidas más arriba se pueden deducir una serie de implicaciones para el estudio arqueológico de la etnicidad. En primer lugar, los planteamientos más tradicionales, dentro de una aproximación histórico-cultural, simplemente ni consideran que semejante cuestión pueda ser objeto de investigación arqueológica. En segundo lugar, desde posiciones escépticas -pero aceptando el interés y la posibilidad de estudiar la etnicidad pretérita- se afirma sencillamente que no existe una relación directa entre etnicidad y cultura material; no hay argumentos para establecer una ecuación de igualdad entre un concepto ya problemático y debatido, "cultura arqueológica", y las manifestaciones materiales de un grupo étnico. Se cuestiona por tanto que los grupos étnicos tengan que ser necesariamente visibles en términos de cultura material. No resulta extraño que desde esta posición se crea firmemente que cualquier investigación sobre la identidad étnica del pasado necesita realizarse a lo largo de otros tipos de evidencias -fundamentalmente textos escritosademás de la arqueología (Hall 1998: 269). Lamentablemente para aquellos casos en que no contamos con fuentes escritas sólo disponemos de los datos arqueológicos. Pero vamos contando con una gran ayuda: los análisis de etnicidad con textos y con datos arqueológicos, como el excelente estudio de Hall (1997) para la Grecia antigua. Eso supone la posibilidad de estudiar cómo se comporta la cultura material en la definición de los antiguos grupos étnicos, al poder tener una evidencia explícita de cuales son los indicadores materiales que se emplean para marcar la etnicidad. Desgraciadamente buena parte de esos indicadores como la lengua (Fishman 1977), las leyes y costumbres, el territorio acotado, las danzas y música, el vestido (Eicher 1995), los adornos y los colores (Gage 1999 y Barber 1999) no dejan huella arqueológica. Y además tampoco deberíamos olvidar que esos indicadores fueron establecidos, en muchos casos, desde fuera de los grupos considerados -es decir, estamos ante definiciones exoétnicas -y lógicamente la interpretatio del extranjero puede ignorar y/o falsear las situaciones reales (Fig. 1).

Con todo, pensamos que el estudio de casos históricos de etnicidad y la ayuda de los casos antropológicos puede ir configurando una línea de exploración de la etnicidad en el registro arqueológico, que vaya construyendo teoría de alcance medio para permitir el estudio de casos estrictamente prehistóricos. Esta sería la tercera alternativa, en la que, aunque se asuma que la identidad étnica se construye socialmente y es subjetivamente percibida (Hall 1997: 19), se acepta por otro lado que los grupos étnicos pueden comunicar su identidad a través de símbolos materiales, consciente o inconscientemente seleccionados de un amplio repertorio cultural, a los que se otorga significación "emblemática" (Hall 1998: 267). Si esto es así, un primer problema es ciertamente cómo reconocer los símbolos materiales de significación étnica de aquellos otros que expresan otras formas de identidades culturales. La única aproximación a este problema es la de realizar un análisis arqueológico contextual que se centre en la manipulación activa de la cultura material por parte de un grupo para expresar límites étnicos (Jones 1998). 


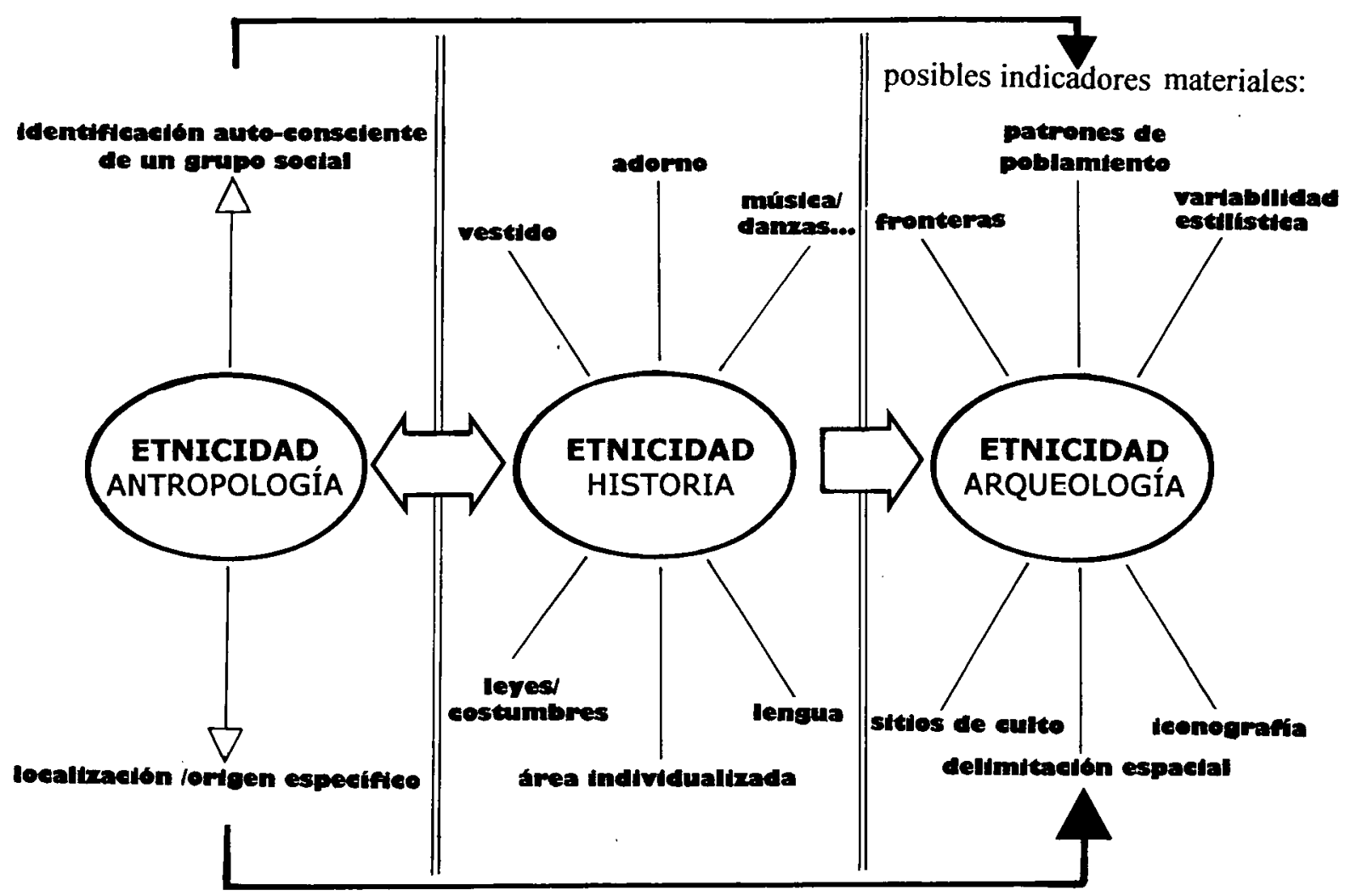

Fig. 1. Características e indicadores de la Etnicidad en Antropología, Historia y Arqueología.

En casos prehistóricos, sin textos para explorar la etnicidad, tenemos que convenir en que para una aproximación arqueológica necesitamos, al menos, dos cosas: primero, que surgiera una identidad de grupo en el pasado, básicamente un reconocimiento consciente de diferencia en oposición a otros, que necesariamente sólo pudo ser construida a través de un discurso hablado, y segundo, que ese grupo utilizara símbolos para marcar los límites étnicos que puedan ser susceptibles de una identificación arqueológica.

Todo lo anterior nos lleva a reconsiderar la naturaleza de la relación etnicidad-cultura material en la línea de la argumentación realizada por S. Jones (1997 y 1998). En primer lugar, el surgimiento de una conciencia étnica depende fundamentalmente de dos hechos: un reconocimiento de experiencias e intereses comunes dentro de un grupo y su necesidad de establecer diferencias frente a otros grupos limítrofes. Para Jones (1998: 273) el reconocimiento de afinidades en experiencias e intereses se fundamenta en las prácticas sociales dentro del grupo, y los símbolos étnicos están así intrínsecamente ligados con las prácticas y relaciones sociales y contienen significados específicos y relevantes (Eriksen 1992, citado en Jones 1998) que moldean la interacción social. Entonces queda claro que la cultura material -junto a otros aspectos de la culturajuega un papel básico a la hora de configurar la producción de representaciones discursivas de identidad. Los límites culturales y étnicos pueden no coincidir, pero la afinidad de prácticas y experiencias ciertamente proporcionan el núcleo sobre el que se construyen nuevos discursos de identidad en circunstancias históricas cambiantes. Como bien indica Jones (1998: 273) "así la arqueología no sólo ofrece una oportunidad para el análisis de los símbolos étnicos sino también para el estudio de aquellas prácticas culturales que configuran la construcción discursiva de la identidad en el pasado". El análisis de cada contexto arqueológico es, por 
tanto, absolutamente necesario, dado que los indicadores étnicos con significados simbólicos no están fijados permanentemente sino abiertos a redefiniciones continuas a lo largo del tiempo. Claro que, también es evidente que cuanto más tiempo haya estado activo un indicador étnico, más posibilidades existirán de que su materialidad sea detectada en el registro arqueológico (Fig. 2).

- Identificación de "cultura arqueológica" : expresión de interacción social a gran escala

Prácticas sociales y experiencias compartidas + oposición a otros grupos

- Elección de símbolos para marcar límites étnicos. Solapamiento indicadores $=$ probable territorio étnico

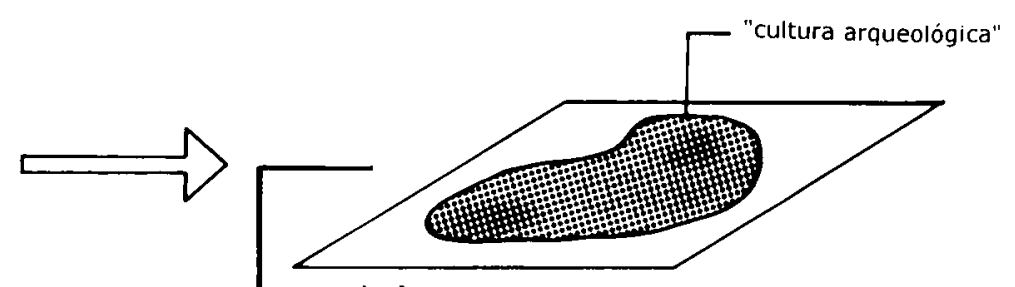

(a)

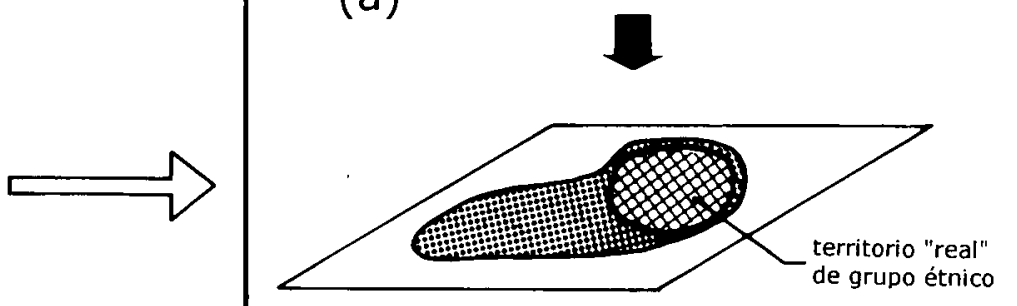

(b)

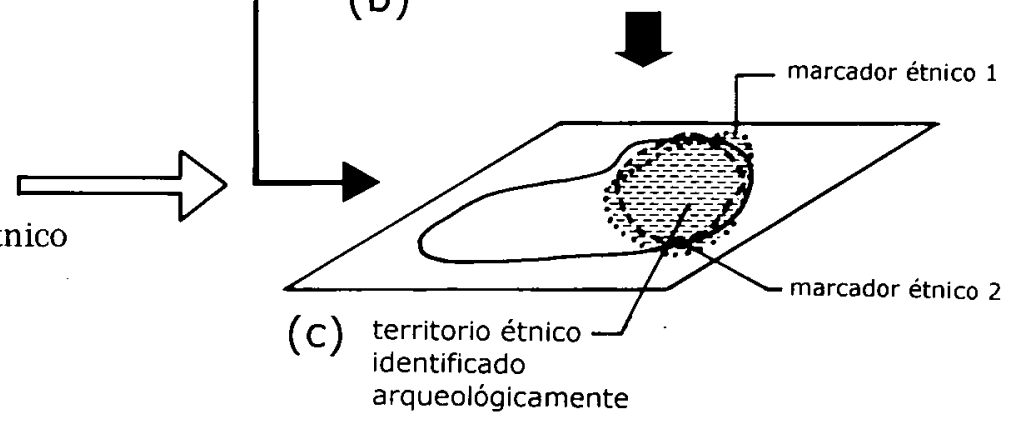

Fig. 2. De la cultura arqueológica a los territorios étnicos.

Es preciso clarificar una cuestión, y es que una cosa es el ethnos - en el más puro sentido griego-definido a priori por la interpretatio de los autores clásicos, y otra cosa es la etnicidad antropológica que se tratar de buscar a través del análisis arqueológico. Una no es reducible a la otra, aunque parece obvio que sólo a partir de la identificación del ethnos se puede plantear el rastreo de la etnicidad. Podemos, por tanto, reconocer una etnia (ethnos) en el proceso de contacto con el mundo romano y analizar los posibles correlatos materiales étnicos. Después, podemos intentar rastrear la existencia de una posible etnicidad en etapas anteriores. Desde luego parece lógico que si existe una realidad étnica atestiguada en las fuentes clásicas, o se acepta que ha surgido enteramente del choque con el "otro", el "romano", o se asume que es el final de un proceso cuya gestación inicial se retrotrae en el tiempo. Y como tal identidad étnica sólo se pudo constituir por oposición a otras identidades étnicas. En otras palabras, este segundo supuesto implica la creencia de que, al menos en la Segunda Edad del Hierro, existió ya un proceso de etnogénesis que funcionó sobre una delimitación territorial y empleó una serie de indicadores o marcadores étnicos simbólicos para separar distintos grupos étnicos. Dentro de ésta hipótesis de trabajo es donde hay que situar el caso de los vettones, uno de los populi identificados por los romanos en las tierras occidentales de la Meseta. 


\section{LOS VETTONES HISTÓRICOS Y LA CUESTIÓN DE LOS LÍMITES}

El primer testimonio literario de contacto de los vettones con los romanos (Livio 35,7,8) relata acontecimientos del año 193 a.C., con la campaña del pretor M. Fulvio junto al lugar fortificado de Toletum (Roldán Hervás 1968-69: 93-94). Aparecen aquí los vettones aliados a sus vecinos del norte, los vacceos, y también a los celtíberos, limítrofes de éstos últimos. Del contenido de las fuentes geográficas se desprende que los vettones ocupaban en este momento un amplio territorio en torno al río Tajo (Plinio N.H. 3,19; 4,113: (...) circa Tagum vettones), extendiéndose al norte casi hasta el Duero, donde limitaban con los vacceos (Estrabón 3,3,2) e incluso con el propio río, que separaba a éstos de los astures (Plinio N-H. 4,112: (...) dein per Arevacos Vaccaeosque disterminatis ab Asturia Vettonibus). La lista de ciudades vettonas proporcionada por Ptolomeo $(2,5,7)$ puede ser otro punto de referencia. De algunas apenas sabemos nada y no puede establecerse su ubicación (Cottaeobriga, Ocelon, Manliana, Deobriga- ¿Ulaca?), de otras pocas sólo existen referencias geográficas aproximadas (Lancia Oppidana-Sierra de la Estrella, Lama-PlasenciaBaños de Montemayor) y el resto se identifica con relativa facilidad (Salmantica-Salamanca, Capara-Ventas de Cáparra, Obila-Ávila, Augustobriga-Talavera la Vieja, Lacimurgi-Navalvillar de Pela), lo cual tampoco significa que estén exentas de problemas (Sayas y López Melero 1991: 77-79, notas 3-6). Lo primero que esto nos plantea es la incorporación de otros núcleos urbanos en la región: es el caso de Bletisama (Ledesma), Mirobriga (Ciudad Rodrigo), Turgalium (Trujillo), Alea (Alia), Caesarobriga (Talavera de la Reina) y Urunia (Irueña, en Fuenteguinaldo), citando sólo aquellos cuyos nombres antiguos nos son conocidos por otras fuentes y es posible identificar.

Pero hablamos siempre de la época que nos transmiten los textos y no de estadios anteriores. Cualquier territorio está sujeto a cambios en el espacio y en el tiempo; puede quedar fijo como marco de referencia pero las variaciones que se dan en el mismo no tienen por qué ceñirse a sus límites. Por tanto creemos necesario prestar atención, a partir de la identificación de los vettones en las fuentes clásicas (Roldán Hervás 1968-69), a la correlación entre los diferentes elementos de la cultura material y los datos del grupo étnico cuyo nombre nos han legado las fuentes (Fig.3). Contamos para ello con la distribución de las esculturas de verracos y de las cerámicas a peine en las altas tierras de Ávila, Salamanca y norte de Cáceres. Ambos elementos delatan la pujanza del "grupo Cogotas II" en un marco geográfico preciso al menos a partir de los siglos IV y III a.C. (Álvarez-Sanchís 1999: 321 ss.). Eso mismo nos lleva a considerar una relación genética con las necrópolis extensas conocidas en la zona y los castros fortificados con piedras hincadas, aunque todavía habrá que deslindar diferencias regionales que subyacen en este modelo.

La frontera septentrional discurriría de este a oeste siguiendo las estribaciones de la sierra de Ávila y el curso del río Tormes hasta su desembocadura en el Duero. El trayecto de este último río por el territorio vettón es no obstante un punto difícil de dilucidar. Probablemente haya que prolongar el límite más al norte, en la provincia de Zamora y al oeste de la mansio vaccea de Sabaria-cerca de Cubo del Vino-abarcando la comarca del Sayago hasta llegar al Duero a la altura del Esla. Es muy significativa la abundancia de esculturas y castros fortificados en este sector, en torno a Fariza, Villardiegua o Moral de Sayago; el mismo argumento vale por supuesto para la margen opuesta, como evidencian los despoblados de Villalcampo y Muelas del Pan. Otro importante dato estriba en la geología del río, muy encajado, lo que debió ser determinante en la configuración fronteriza de la zona. Exactamente en el espigón formado por el Duero y el Esla se situaría el triple confín entre astures, vacceos y vettones (Esparza 1986: 136-137), aunque sobre este punto hay quienes prefieren seguir la línea del Tormes (Roldán Hervás 1968-69: 101; Sayas y López Melero 1991: 79-80). 


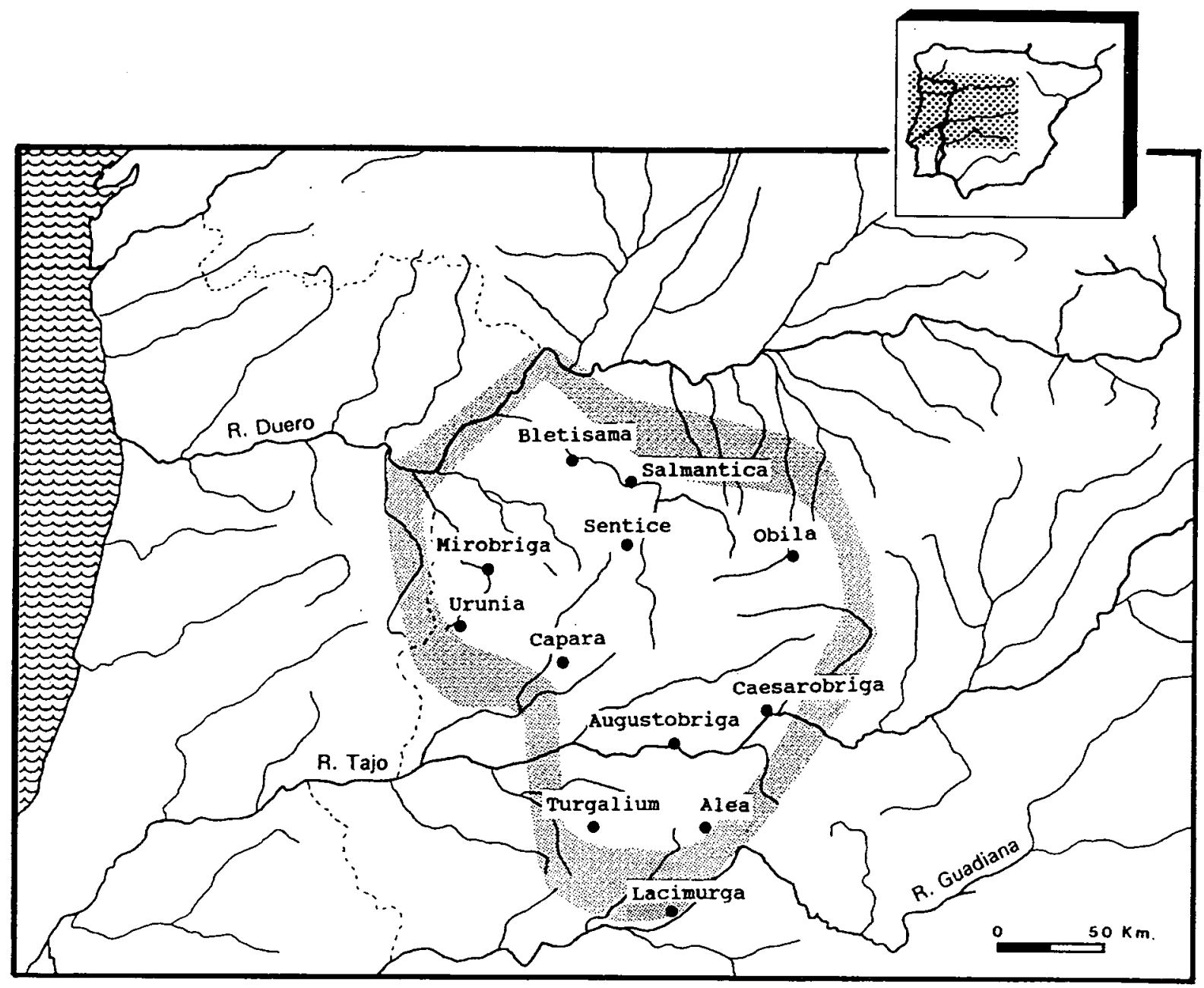

Fig. 3. Límites geográficos de los Vettones según las fuentes y principales ciudades identificadas adscritas al territorio (según Álvarez-Sanchís 1999).

Los asentamientos fortificados que jalonan de norte a sur el oeste de la provincia de Salamanca, desde Nuestra Señora del Castillo en Pereña hasta Irueña en Fuenteguinaldo, son suficientes a nuestro modo de ver para casi garantizar la existencia de una división territorial con los lusitanos en torno a los ríos Coa y Águeda, aunque si ésta no existiese la distribución de los verracos nos llevaría de nuevo a la misma conclusión. Este último hecho es fundamental, en la medida en que los testimonios escultóricos más occidentales conocidos, Almofala y Cástelo Mendo en la Beira Alta, Barquilla y La Redonda en Salamanca, no traspasan la línea de los ríos citados. Esta misma explicación podría ser válida para el límite suroccidental, pero aquí la ubicación de algunas ciudades conocidas, tanto vettonas (Capara) como lusitanas (Rusticana, Norba Caesarina) facilitan el trayecto, que se prolongaría hasta el Tajo. Una línea teórica continuaría entonces entre Cáceres y Trujillo hasta la sierra de Guadalupe. La ausencia de verracos al oeste del trazado es la nota dominante. Hallazgos recientes en las comarcas de Valencia de Alcántara y Marvâo trasgreden lo dicho, pero difícilmente su tipología es comparable al resto. En este contexto también es interesante hacer referencia a la inscripción lusitana de Arroyo de la Luz (Tovar 1985), la más oriental de los testimonios conocidos y a escasa distancia del territorio en cuestión. 
Hay cierto consenso en aceptar la extensión de los vettones prácticamente hasta la margen derecha del Guadiana. Sin embargo la cuestión entra en conflicto con la escasa distribución de verracos en la zona y la ausencia de otros elementos arqueológicos que, como la cerámica a peine, a duras penas trasgreden el sur del Tajo, problema que consideraremos a continuación. Una explicación paralela vale para la frontera oriental, que iría desde la Sierra de Altamira y los Montes de Toledo a buscar la línea del Tajo, en un punto cercano al este de Caesarobriga (Talavera de la Reina), para seguir en dirección Norte entre las sierras de Gredos y Guadarrama, remontando el Alberche, y dibujar así una línea sensiblemente igual al límite actual de las provincias de Ávila y Madrid. Las sólidas evidencias epigráficas y arqueológicas aportadas por González-Conde (1986) implican admitir que el límite entre vettones y carpetanos cruzaba nítidamente de norte a sur el occidente de la provincia de Toledo. Al oeste de esta línea la abundancia de verracos está clara-S. Martín de Pusa, Carrascalejo, Torrecilla, Las Herencias, Talavera de la Reina, Castillo de Bayuela-. Unos pocos rebasan el límite (Gálvez, Totanés y Argés) pero son minoritarios. En Ávila, el trazado continuaría con las estatuas que jalonan las dehesas del oriente provincial hasta la comarca del Amblés: Guisando, Gemiguel, Alamedas Altas, Bernuy Salinero, Santo Domingo de las Posadas... Proliferan aquí castros de la Edad del Hierro -Ulaca, La Mesa de Miranda, Las Cogotas, Ávila-Obila- cuya historia arqueológica conocemos lo suficiente como para deducir el protagonismo histórico de una comarca que concentró a la población y que pudo alcanzar una relativa alta densidad de poblamiento (Ruiz Zapatero y Álvarez-Sanchís 1995 y 1999). El trazado en esta zona es coherente con el límite oriental del conventus Emeritensis, al oeste de Guadarrama, que seguiría el cauce de los ríos Alberche, Cofio y Voltoya, hasta unirse con el límite sur del conventus Cluniensis, no lejos de Adanero (Hernando Sobrino 1995: 88-89).

Si las evidencias que tenemos son relativamente sólidas como para deducir los límites norte, este y oeste de la región, la cuestión se diluye cuando abordamos el trazado meridional. Las fuentes no vinculan a los vettones con el Anas, aunque una fuente posterior (Prudencio peristeph., 3) relaciona a éstos con la ciudad de Emerita. Para el extremo suroriental se puede recurrir a la discutida ciudad vettona de Lacimurga o Lacimurgi transmitida por Ptolomeo (2,5,7) e identificada en el cerro Cogolludo (Navalvillar de Pela, Badajoz), en la orilla derecha del Guadiana. De ser cierta esta atribución nos pondría ante un hecho cronológico posterior; no en vano ha de ponerse en relación, y además con un valor mucho más directo:

(a) La heterogeneidad de los documentos arqueológicos. Al sur del Tajo pueden apreciarse tendencias contrapuestas: la cerámica a peine apenas está representada en el territorio mientras la pintada a torno denota una mayor afinidad con las poblaciones turdetanas. La documentación arqueológica encuentra asimismo réplicas adecuadas en las esculturas de verracos-Villasviejas en Botija, Torrequemada, Madrigalejo-cuyos vínculos formales y decorativos están en deuda con la escultura ibérica, lo que no deja de plantear problemas a no ser que se acepte en este momento una divisoria étnica en torno a las márgenes del Tajo/Almonte.

(b) La atribución del suelo en época romana, con traslados forzosos de las poblaciones indígenas y la adscripción o restitución de núcleos urbanos a etnias diferentes, contrariedades que se explican en parte al tratarse de ciudades fronterizas. La mención de Prudencio a comienzos del siglo V d.C. (Perist. 3,186), que se refiere a Mérida como clara colonia Vettoniae -pero recordando que al menos Estrabón $(3,2,15)$ la designa túrdula - y la argumentación expuesta por Abascal (1995: 101 ss.), según la cual Turobriga sería ciudad vettona adscrita al territorio emeritense, nos pondría así ante una nueva realidad y en relación con la administración.

Resumiendo, las evidencias arqueológicas permiten individualizar un territorio con entidad propia entre las cuencas del Tormes/Duero y el Tajo que cabe considerar como el área nuclear de la Vettonia durante la Segunda Edad del Hierro. La estructura fronteriza podría haber alcanzado cierto grado de consolidación en los siglos IV-III a.C., como se infiere de la distribución de las cerámicas incisas a peine y las esculturas de verracos. La geografía de estos elementos es sin embargo más restringida que la postulada por la lingüística 
y las fuentes clásicas, que reflejarían un estadio no anterior a los siglos II-I a.C. Este momento podría relacionarse con algunos desplazamientos celtibéricos en la región meridional del Tajo, como evidencia la ceca celtibérica de Tamusia en Botija (García-Bellido 1995), que tal vez implique otros traslados migratorios llegados del norte coincidiendo con la fase de esplendor de los poblados tipo oppida. La asignación étnica de estas tierras a los vettones, en torno a las sierras de Montánchez y Guadalupe y su proyección hasta el Guadiana, podría tener aquí y a partir de este momento una explicación más coherente. En un marco más general esta expansión es la que documenta Plinio (N.H.3,13-14), al recordar que los celtici de la Bética procedían de los celtíberos de Lusitania con su lengua, religión y los nombres de sus poblaciones.

De la situación esbozada más arriba se deduce que los verracos y las cerámicas con decoración a peine son dos indicadores simbólicos útiles para explorar su utilización desde inicios de la Segunda Edad del Hierro. Los verracos, entre otras cosas, traducen la importancia del ganado en la estructura socioeconómica y simbólica de los vettones y al mismo tiempo "construyen" a nivel espacial macro el paisaje de esta estructura social. Se ha destacado la importancia que las economías especializadas pueden tener en algunos procesos étnicos (Burillo 1998: 139), en los que el grupo étnico se circunscribe a un territorio de características económicas concretas. De hecho veremos cómo en las áreas ajenas al territorio característico de los vettones aunque existan esculturas de piedra, éstas adquieren unos rasgos que claramente las diferencian de las del área nuclear vettona. Los marcadores simbólicos pierden aquí su significación originaria y se difunden con rasgos estilísticos distintos y funciones distintas. Por otro lado las cerámicas con decoración a peine, producción cerámica característica del área vettona, constituyen un marcador móvil de la etnicidad vettona. Aquí también podemos distinguir un área estrictamente vettona con unos rasgos estilísticos y técnicos bien diferenciados, y otras áreas donde estas especies cerámicas se difunden como productos o como estilos imitados y pierden por tanto esa connotación inicial de marcador simbólico étnico. Si los verracos materializan la etnicidad en el paisaje, las cerámicas a peine la construyen en las relaciones sociales cotidianas a través de la visualización de las composiciones decorativas y los mensajes icónicos que éstas encierran.

\section{APROXIMACIÓN ARQUEOLÓGICA A LA ETNICIDAD VETTONA PREHISTÓRICA (I): LOS VERRACOS}

La escultura zoomorfa fue un episodio importante en la organización del territorio vettón durante la Segunda Edad del Hierro. Las estatuas personifican algunas de las creencias más básicas de la sociedad, y tienden, por tanto, a moldear la experiencia de aquellos que las "usan" y "viven" en sus alrededores. Hay indicios de que algunos sitios importantes en el paisaje de la época fueron subrayados mediante la erección de estas esculturas. Monumentos que además han perpetuado ulteriores desarrollos en el paisaje, pues se extienden desde límites de parcelaciones hasta divisiones actuales de territorios, hallándose también junto a las puertas y recintos de los poblados fortificados.

La imbricación de esta plástica en el universo socio-económico del poblamiento de la Edad del Hierro nos dio importantes resultados en el valle abulense de Amblés, habiendo relacionado su construcción y emplazamiento con la expresión simbólica de una élite que controla ganados, agua y los mejores pastos (Álvarez-Sanchís 1994 y 1998). Un segundo nivel de lectura desde una perspectiva microlocacional-toros de Villanueva del Campillo y Tornadizos en Ávila-nos permitió descubrir recientemente los complejos factores visuales de las esculturas en el paisaje, que no resultan, desde esta óptica, un mero soporte pasivo (Álvarez-Sanchís y Ruiz Zapatero 1999). Este modelo, que responde a un uso socializado del medio natural y valora la jerarquía fijada en los patrones de asentamiento, tiene también su reflejo en la cuenca media del Tajo y en el occidente de la provincia de Salamanca. 
Es importante destacar la concentración de verracos en estas comarcas (Álvarez-Sanchís 1999: 281 ss.). En el Amblés la dispersión contrasta con el vacío hacia el Este del valle-frontera de vettones y carpetanoscon las poquísimas esculturas conocidas hacia el Norte -tierras cerealistas del Duero, ya de transición a las comunidades vacceas-con el Oeste o con el Sur, donde la Sierra de Gredos constituye una gran frontera natural. En este sentido, cabría sospechar que el valle formó una cierta unidad para las comunidades que lo habitaron durante las últimas centurias del primer milenio a.C.. Debió ser un área que concentró a la población y pudo alcanzar una relativa alta densidad de poblamiento. La nómina de emplazamientos conocidos en el Tajo medio es también evidente si se compara con los escasos ejemplares al este de Caesarobriga (Talavera de la Reina) -tierras limítrofes carpetanas-al norte-Campo Arañuelo-y al sur-Sierras de Guadalupe, Altamira y Montes de Toledo--. De nuevo se vislumbra una ocupación coherente que articula la distribución espacial de los poblados, las esculturas y los recursos. En tierras del Yeltes-Huebra y del Águeda, en la provincia de Salamanca, la dispersión de los verracos de nuevo se asocia a un paisaje granítico de pastos y encinas. El número de emplazamientos conocido es más escaso respecto a sus homólogos abulenses, pero debe reseñarse la significativa ubicación de los ejemplares más occidentales (Barquilla, La Redonda, Gallegos de Argañán, Fuenteguinaldo) quienes, junto a las vegas citadas, "separan" estas tierras de las tradicionalmente consideradas lusitanas, ya en la frontera portuguesa.

La densidad de estos monumentos difiere en cada comarca, lo que pone de manifiesto que este fenómeno ostenta en cuanto a número de piezas zonas de diferente rango (Fig. 4). Otro tanto puede decirse desde el punto de vista estilístico. Trasladando los verracos a un mapa del occidente de la Meseta se aprecian cuatro grandes ámbitos: (1) entre el Minho y el Tua, que se correspondería con la distribución de las cabezas zoomorfas exentas, (2) entre el Tua y el Duero, con esculturas de pequeño y mediano tamaño y talla esquemática, (3) entre el Tormes y el Tajo, con el conjunto de esculturas más monumentales, abarcando el área nuclear de los vettones, y (4) entre el Ruecas y el Almonte, con pocos ejemplares y muy individualizados en general. Existe la complicación adicional de que artesanos de distinta formación hubieran coexistido en el espacio y en el tiempo. En cualquier caso, sí nos parece importante señalar cómo la homogeneidad de algunos talleres escultóricos podría indicarnos que la elite debió mantener relaciones entre sí, compartiendo una simbología común y, probablemente en muchos casos, unos mismos artistas. Los grandes toros con soporte central del valle de Amblés (Las Cogotas, La Mesa de Miranda, Ulaca) tienen suficiente entidad para acreditar lo dicho. Es decir, no sólo existirían relaciones verticales de tipo gentilicio, sino también horizontales, haciendo coincidir un mismo tipo de escultura como identificador de los nobles de uno o varios asentamientos.

Tenemos por otro lado indicios de límites, parcelaciones y cañadas que fueron identificados mediante su emplazamiento. Varios ejemplos de esta naturaleza se producen en la linde que divide los términos municipales de Toledo y Cáceres, como el toro de Madrigalejo, entre el término citado y el de Navalvillar de Pela en Badajoz (Ramón y Fernández Oxea 1950, 64), el verraco de Carrascalejo de la Jara, hallado en la línea de demarcación de Carrascalejo, Villar del Pedroso y Mohedas de la Jara (id. 1950: 59), o las esculturas de la Finca "la Oliva", en un cerro sito entre los términos de Villar del Pedroso y Valdelacasa de Tajo (González Cordero y Quijada 1991: 178). Extremadamente elocuente en este mismo sentido es la localización, no lejos de la línea de demarcación entre Ávila y Madrid, de los Toros de Guisando. Incluso, se puede recurrir a la tradición recogida en 1896 por Ballesteros (o. cit. en Rodríguez Almeida 1981: 19), relativa a la existencia en el límite oriental de Ávila de una escultura de verraco con una inscripción doble en los costados: Hic est Tarraco, non Lusitania/Hic est Lusitania, non Tarraco, epígrafe cuyo fundamento podría residir en un término romano del puerto de La Palomera, al norte de Cebreros (Rodríguez 1879: 60), que deslindaba los límites con análoga inscripción. En las proximidades se localiza además el río Cofio, afluente del Alberche, que podría derivar del latín cofinium, "confín" o "frontera"(Knapp 1992: 7). Resulta lógico pensar, a partir de estos aspectos, que otras veces las esculturas coincidan con los límites teóricos de los territorios de los oppida de la Edad del Hierro ofrecidos por los polígonos Thiessen, bien evidenciado en el valle de Amblés (Ruiz Zapatero y Álvarez-Sanchís 1995: 228). 


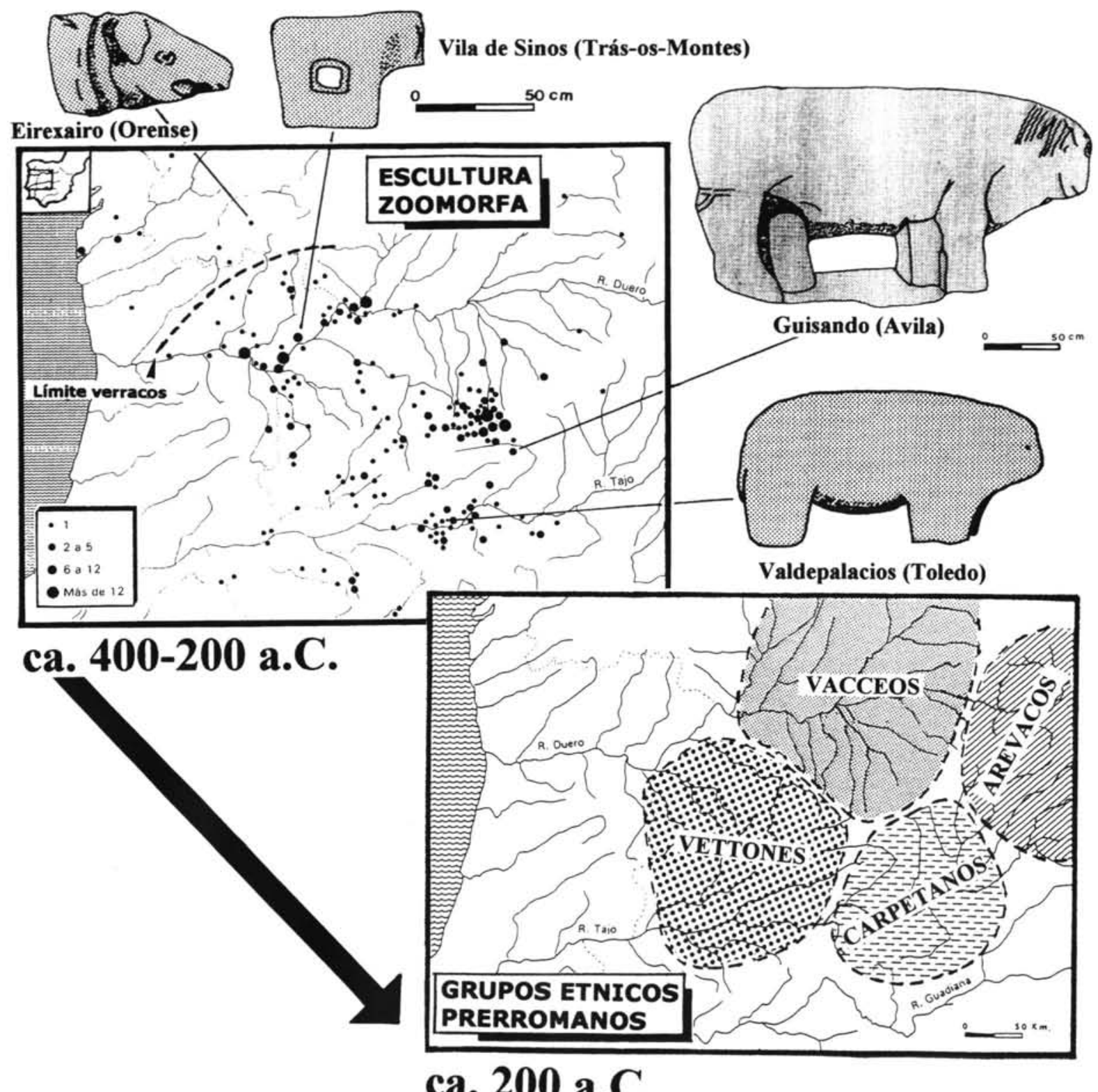

Fig. 4. Distribución de esculturas zoomorfas en el área vettona (según Álvarez-Sanchís 1999) y limítrofes y su relación con los territorios de los populi del centro peninsular.

Todos estos datos ofrecen una lectura abierta que permite entablar un debate sobre la función simbólica, apotropaica y territorial de los verracos, esto es, (1) flanqueando los accesos a los poblados, tal vez con la simbología escatológica de guardianes benefactores que se documenta en todo el Mediterráneo, (2) regulando el acceso a los pastos de la parte baja de los valles, donde la alimentación del ganado entra en competencia con los cultivos, y (3) delimitando el territorio ocupado, lo que otorga a la escultura un significado emblemático para "marcar" etnicidad. Las elites de las comunidades prerromanas erigieron estos monumentos 
como símbolo de su posición social y para legitimar sus derechos sobre el territorio; una forma de ordenar el "agrios" en la Segunda Edad del Hierro, por lo menos desde el afianzamiento de los castros en el siglo IV a.C. hasta la consolidación de los grandes oppida en las postrimerías de la conquista romana. Debieron existir otras fórmulas de representación en las fronteras, en las puertas de las ciudades y en el campo, que simbolizarían mágica y socialmente a los grupos residentes y a los grupos propietarios de ganado, pero carecemos de la información arqueológica necesaria para completar este panorama.

Con el tiempo, la monumentalidad y el panteón de estas figuras se fue modificando, hecho que coincide con el ámbito hispanorromano. Ahora nos encontramos con monumentos funerarios inspirados en las esculturas indígenas, más geométricos pero con los rasgos consustanciales a genuinas cupae (Martín Valls y Pérez Herrero 1976). La especificidad tipológica y geográfica de estas producciones también es extensible en cronología tardía a las cabezas zoomorfas exentas del NO., con un sentido doméstico y familiar como así se deduce de su vinculación a las paredes de las viviendas castreñas (Taboada 1949: 17-18), pero con rasgos que las diferencian claramente del territorio vettón. Al cambiar la sociedad y las relaciones de poder los verracos pudieron perder parte de su función original. En todo caso, la identificación auto-consciente del grupo pudo seguir implícita a través de las escasas piezas que presentan inscripciones latinas, utilizadas para reflejar la onomástica o estructura familiar de estos vettones romanizados.

\section{APROXIMACIÓN ARQUEOLÓGICA A LA ETNICIDAD VETTONA PREHISTÓRICA (II): LAS CERÁMICAS A PEINE}

De seguir a Delibes y Romero (1992: 251 ss.), es evidente que hay que pensar en un desarrollo sin solución de continuidad para estas célebres cerámicas del valle del Duero desde contextos Soto de la Primera Edad del Hierro. Esa misma lectura puede aplicarse a la zona suroccidental de la cuenca, al otro lado de las sierras centrales, de donde proceden algunos de los conjuntos más representativos (Martín Valls 1985; GonzálezTablas 1990; Álvarez-Sanchís 1999). Sólo así cabe entender la relación que se observa entre los vasos a peine de Sanchorreja, el cerro de San Vicente, el poblado del Picón de la Mora, La Mota o Cuéllar. Sus posibilidades formales no evitan la impresión de una cierta similaridad desde el punto de vista compositivo y un aspecto muy peculiar en su producción, que deriva esencialmente de cinco rasgos: (1) la predilección por ejecutar motivos sencillos, bandas en zig-zag y sogueados, (2) la decoración también en el interior de las vasijas, estilo que nos remite a las cerámicas pintadas y de tradición del Bronce Final, (3) el tipo de peine empleado, casi siempre inciso, lo que a la postre será característico del grupo Cogotas II, (4) la composición, que abarca la mayor parte de la superficie del vaso, y (5) el repertorio de formas, reducido a cuencos, platos y vasos de tendencia carenada.

Con todo, la plenitud de estas cerámicas se corresponde a la Segunda Edad del Hierro, como ya propusiera Martín Valls (1986-87: 74) hace algunos años y confirman plenamente los ajuares de las necrópolis vettonas. En primer lugar, cabe señalar la comparecencia del peine en tumbas con espadas de antenas atrofiadas, como la tumba 63 del Raso o los conjuntos 185 y 200 de la zona VI de La Osera (Fernández Gómez 1986: 718-724; Cabré et al. 1950: 110-113). Otro tanto cabría decir del material importado asociado a estas cerámicas, pudiéndose citar los dos pequeños platos de barniz negro de la sepultura I de La Osera (zona I, túmulo D), adscribible a la forma 21 de Lamboglia y fechados en el segundo cuarto del s. IV a.C. (Cabré y Morán 1990: 78 y 80), o el platito campaniense de la tumba 338 de la zona VI de La Osera, bien datado por Martín Valls (1986-87: 73) en el s. III a.C. siguiendo la tipología de Morel.

Este mismo proceso, de copiosa bibliografía y que sería prolijo enumerar, debió ser general en todos los castros vettones de la cuenca suroccidental (Salamanca, Ledesma, Las Paredejas, Picón de la Mora, Yecla de Yeltes....). La situación es, sin embargo, más compleja en la Meseta Norte. Tales cerámicas cubren 
la práctica totalidad del valle del Duero, desde el castro astur de Labradas, al oeste del Esla (Esparza 1986: 341), hasta la necrópolis celtibérica de Luzaga (Díaz 1976: fig. 20, $n^{\circ} 12$ ). En La Mota y Cuéllar evolucionan sin solución de continuidad desde los niveles del Soto, aunque es muy llamativo el incremento que se detecta en los estratos más recientes, que se han fechado en los siglos IV y III a.C. (Seco y Treceño 1993: 142-143; Barrio 1993: 197-207). Fechas en consonancia con éstas proceden asimismo de algunos conjuntos cerrados, como la tumba 28 de la necrópolis vaccea de Padilla de Duero, asociada a un puñal de tipo Monte Bernorio y una espada tipo Miraveche que proporcionan un buen punto de referencia fechable a finales del s. IV a.C. (Sanz Mínguez 1993: 379-386), o las sepulturas 13 y 40 de la necrópolis arévaca de La Mercadera, que coincidirían con el máximo desarrollo del cementerio a lo largo de la cuarta centuria o inicios de la siguiente (Lorrio 1990: 48). La necrópolis de Carratiermes brinda asimismo interesantes ajuares donde la comparecencia de cerámicas a torno y fíbulas de La Tène I-II junto a las decoradas a peine es habitual en esos siglos (Altares y Misiego 1992: 550-551).

Quiérese decir con estos ejemplos, que desde la cuarta centuria a.C. estas cerámicas se están proyectando en el sector centro-oriental de la Meseta, beneficiándose a un mismo tiempo de las cronologías sugeridas por las necrópolis vettonas más ricas (Fig. 5). Su ausencia, sin embargo, en el castro del Raso de Candeleda, bien datado a inicios del siglo II a.C. (Fernández Gómez 1986), así como en el alfar del segundo recinto de Las Cogotas, que puede llevarse sin problemas a partir de esas fechas (Ruiz Zapatero y Álvarez-Sanchís 1995), demuestra que las especies a peine son anteriores a la fase final de los grandes oppida abulenses. Los datos de Ulaca y La Mesa de Miranda son más imprecisos pero también pueden servirnos como punto de referencia. El primero ha proporcionado escasísimos fragmentos, y el dato parece firme dada la intensidad de las prospecciones superficiales realizadas (Ruiz Zapatero y Álvarez-Sanchís 1999). Por otra parte, Martín Valls (1986-87: 73) destaca que cuando se amplía el último recinto de La Mesa, fosilizando una parte de la necrópolis con las características cerámicas, esta zona debía de estar en desuso. Por tanto, la fecha de la construcción de la muralla, seguramente en la primera mitad del s. II a.C., daría una data ante quem para las peinadas en las penillanuras occidentales de la Meseta.

Si este desarrollo justifica hablar de una etapa de madurez para la cerámica a peine, desde el punto de vista del estilo merecen señalarse otras novedades respecto al Hierro Antiguo:

(a) una composición más variada en las decoraciones: motivos de cestería, sogueados, series en zig-zag, espigados, festones, aspas, semicírculos y bandas, que pueden aparecer simples o combinados,

(b) técnicas distintas asociadas al peine, en particular oquedades, gallones, estampillados y acanaladuras,

(c) la distribución de los motivos, en general en la zona media-alta del vaso y reservando la base para las decoraciones radiales,

(d) se incorpora el peine impreso, predominantemente inciso hasta la fecha, aunque lo normal es recurrir a la fórmula mixta,

(e) desaparece, o se rarifica, la decoración en el interior de los vasos,

(f) su asimilación a cuencos hemisféricos y troncocónicos sigue siendo habitual, pero se diversifican más los tipos: urnas de perfil en S, vasos ovoides, globulares, copas y-recipientes de cuello cilíndrico,

Un aspecto que consideramos muy importante es la búsqueda de estilos decorativos normalizados en el ajuar funerario. Lorenz (1985) planteó una interesante aproximación arqueológica al estudiar el vestuario de las tumbas de La Tène inicial en Centroeuropa, demostrando que los objetos más significativos (armas y adornos) permitían descubrir tradiciones geográficas específicas, al tiempo que expresaban identidades de grupo y estatus. De igual manera, para el caso que nos ocupa, un detallado análisis estilístico de las cerámicas con decoración a peine podría evidenciar características atribuibles a una o varias comunidades vecinas, así como la red social a la que pertenecen (Plog 1978 y 1980). Son muy complejas las razones por las que se debieron decorar los recipientes cerámicos (Braun 1991; David et al. 1988) pero ya desde los años 70 se destacó la estrecha relación entre decoración cerámica e interacción social (Friedrich 1970). 


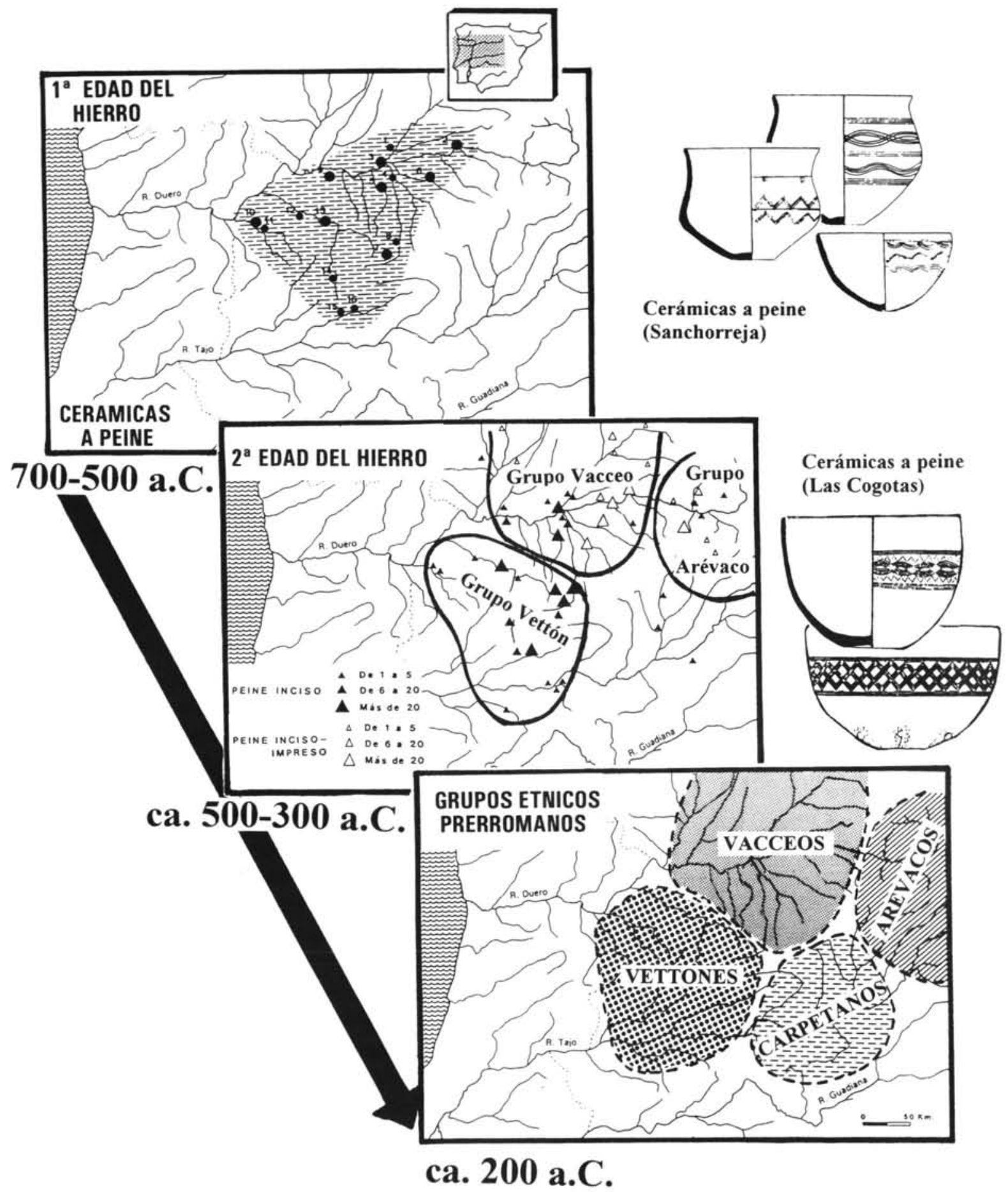

Fig. 5. De las cerámicas a peine a las etnias prerromanas del centro de la Península Ibérica. 
Desde esta perspectiva se han establecido métodos para estudiar la variabilidad estilística de las decoraciones cerámicas (Härdth 1986-86; Hole 1984) y se han realizado brillantes aplicaciones a contextos de la Edad del Hierro europea (Rowlett 1989; Van Heeringen 1989; Wells 1998). La dimensión específica de la etnicidad en la cerámica se ha discutido desde estudios etnoarqueológicos (Sterner 1989), aproximación desde la que hay muchas cosas que aprender, empezando por algo tan elemental como la consideración de la vida media de los recipientes cerámicos (Mayor 1991-92).

El estudio y dispersión de las cerámicas a peine ha merecido distintas visiones de síntesis (Hernández 1981; Martín Valls 1986-87; Barrio 1988; García Soto y De la Rosa 1990; Álvarez-Sanchís 1999). No obstante, debe ponerse de manifiesto que la mayor parte de los testimonios de las cartas de distribución corresponden a yacimientos con una muestra escasa, por lo que debemos ser prudentes a la hora de deducir la expansión de un grupo sin valorar su incidencia en términos cuantitativos. Usando criterios numéricos existe la posibilidad de abarcar diferentes niveles de análisis que discriminen: (a) las técnicas, (b) los motivos, (c) las formas asociadas y (d) el contexto de hallazgo (poblado/necrópolis). Las cerámicas a peine no sólo nos hablan del artesano que las fabrica y decora; constituyen un código de información sobre la identidad del grupo-social, de género y territorial-al que pertenece. Hodder (1982) destaca que cuando los recipientes se utilizan para señalar la adscripción a un grupo determinado, éstos deben ser visualmente diferentes a los ostentados por otros grupos.

Cabría partir en primer lugar de los motivos más sencillos, como las series de bandas en zig-zag que son comunes a todo el valle del Duero y el Sistema Central, y cuya génesis tal vez haya que relacionar con las cerámicas incisas y pintadas del Bronce Final y de la Primera Edad del Hierro. A partir de ahí podrían discriminarse técnicas específicas en función del peine empleado y sus implicaciones desde el punto de vista territorial. La coincidencia entre las producciones incisas del ámbito vettón (Las Cogotas, La Mesa, El Raso, Salamanca, Villanueva de la Vera) y un gusto más acusado por las cerámicas impresas o incisoimpresas en las comunidades vacceas y arévacas (Coca, Cuéllar, Padilla, Olivares de Duero, Roa, Tiermes, Luzaga) tiene suficiente entidad para acreditar lo dicho. Otro indicio en este mismo sentido sería la predilección por los temas en espiguilla y líneas de puntillado en las necrópolis del Alto y Medio Duero, frente a las barrocas cesterías de Cogotas II. Finalmente no debe excluirse, sino todo lo contrario, el recurso a los análisis microlocacionales o de sitio. De manera breve, su estudio en las necrópolis de Las Cogotas, La Osera y El Raso de Candeleda (a partir de los datos de Cabré 1932; Cabré et al. 1950 y Fernández Gómez 1986) permite esbozar algunas consideraciones (Fig. 6).

Estas cerámicas suponen respectivamente el $6 \%, 11 \%$ y $17 \%$ del total de enterramientos conocidos. En el primero contamos con 97 tumbas que incluyen estos recipientes, generalmente cuencos hemisféricos y vasos ovoides, 17 de las cuales se relacionan con otros elementos de ajuar. Los cuatro motivos más abundantes proporcionan las siguientes frecuencias: temas de cestería (38\%), bandas en zig-zag (23\%), soles o estrellas $(15 \%)$ y sogueados (12\%). Si pasamos a la zona sexta de la Osera, nos encontramos con un total de 59 enterramientos con cerámica a peine, de los que 37 tienen ajuar. Los vasos se relacionan con soportes análogos y urnas de cuello cilíndrico; sin embargo, las tendencias estilísticas apuntan en otra dirección: básicamente se trata de sogueados $(60 \%)$, bandas en zig-zag (10\%), sogueado/zig-zag (7\%) y cestería (3\%). La situación es particularmente interesante en las 12 tumbas del Raso con cerámica a peine, dándose la circunstancia de que todas ellas tienen ajuar. Las formas están más diversificadas, sobre todo urnas de cuello cilíndrico y de perfil en S, y el cambio también parece darse en la sintaxis decorativa: motivos almendrados (50\%) -acanaladuras verticales delimitadas por líneas incisas a peine-bandas en zig-zag (18\%), sogueados $(9 \%)$ y bandas horizontales o verticales $(9 \%)$. Esta flexibilidad también se constata si consideramos el número de púas usado en los peines, aunque plantea problemas insolubles si se tiene en cuenta el grado de conservación de las piezas y la fiabilidad de la documentación aportada. De todas maneras, en una primera apreciación, los peines de 2 y 3 púas acaparan más de la mitad de la muestra en Las Cogotas. En el Raso se podrían situar entre 3 y 4 , mientras La Osera reclama sobre todo modelos de 4 y 5 púas. 


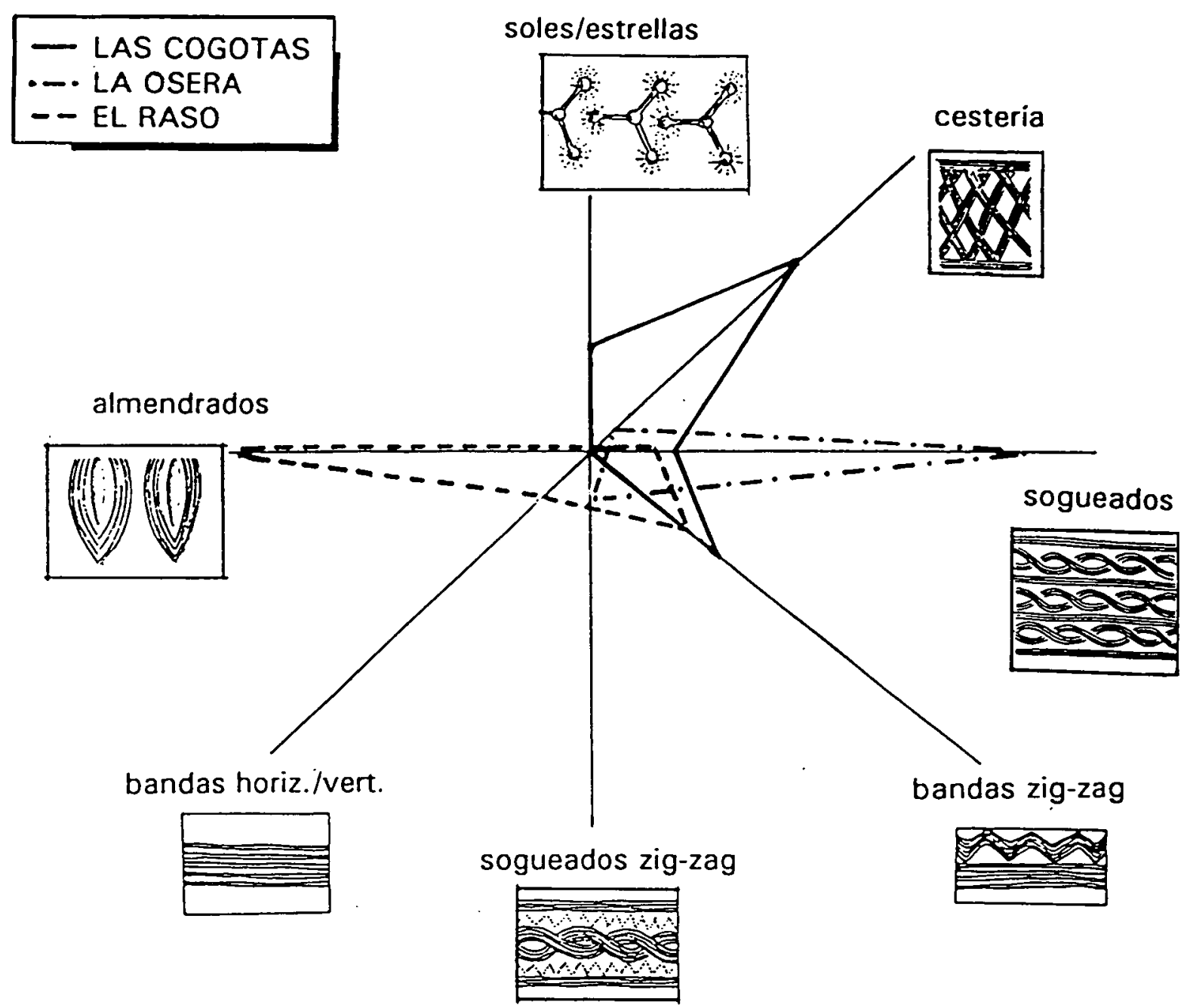

Fig. 6. Motivos de las cerámicas a peine y diferencias estilísticas a nivel de asentamiento.

La impresión que se obtiene es que existen marcadas diferencias estilísticas a nivel de asentamiento. En general, puede afirmarse que los temas más importantes se repiten en casi todos ellos, pero su cuantificación es muy diferente e incide sobremanera en la ordenación de los conjuntos. De un análisis detallado de las cerámicas a peine se puede plantear entonces la existencia de:

(a) motivos comunes de la tradición cerámica, que se repiten en todos o casi todos los sitios,

(b) motivos y técnicas característicos de algunas comarcas o regiones,

(c) motivos predominantes y otros exclusivos de algunos asentamientos.

Que talleres vettones, vacceos y arévacos desarrollen tradiciones decorativas distintas podría ser un buen reflejo del deseo de estos grupos de demostrar su identidad y etnicidad a través de estos símbolos visuales. Pero la identificación de motivos "comarcales" y de "sitio" revela también que existió alguna forma de separación o diferenciación intencional entre las comunidades vettonas. Con estos datos, pensamos que a partir de la decoración de las cerámicas se podrían entrever prácticas e identidades de los grupos 
de parentesco en el territorio. Probablemente reproducen estampados de telas que sin duda se relacionarían con otros elementos accesorios del vestuario, y es también muy posible que estos mismos rasgos denoten códigos de información de género entre sus propietarios. Las decoraciones aparecen en tumbas masculinas y femeninas, sin que ello marque necesariamente diferencias de riqueza en los ajuares, pero nos parece del todo evidente la relación de estos recipientes con algunas de las tumbas de guerrero más suntuarias. Este modelo sería consistente con la idea de los verracos, expresión de una iconografía política que incluye información sobre identidades grupales y su competición por el acceso a recursos económicos restringidos.

\section{REFLEXIONES FINALES}

Las hipótesis presentadas en este trabajo sugieren líneas interesantes para investigaciones futuras. La tesis central es que existen posibilidades de acercarse a la etnicidad del pasado a través de la cultura material. Los elementos visuales como las esculturas zoomorfas o ciertas especies cerámicas decoradas pudieron -entre otras cosas-tener el valor de "marcadores" étnicos, valor que hay que intentar (de)mostrar a través de un análisis contextual. En el caso de los verracos y las cerámicas a peine los pasos siguientes serían:

(1) Desarrollar un sistema de datación de las esculturas más allá de la seriación estilística, quizás buscando apoyo en las ocupaciones de los asentamientos "vinculados" a los verracos o por otros procedimientos, para establecer el primer horizonte cronológico en el empleo de estas manifestaciones escultóricas por las comunidades del Occidente de la Meseta. La determinación de la extensión y distribución de las esculturas en ese primer momento ayudaría a caracterizar la emergencia de una conciencia étnica.

(2) Explorar la posible existencia de límites "conflictivos" en los que pudo ser necesario "marcar" de una forma más contundente no sólo el uso de recursos subsistenciales sino también las "fronteras" con otros populi. A juzgar por el mapa de distribución de esculturas zoomorfas (Fig. 4) los posibles límites "fronterizos" evidenciados por la fuerte concentración de esculturas son tres: por un lado, al Noroeste la línea del Duero, en segundo lugar hacia el Este el grupo abulense del Amblés y aledaños, y por último al mediodía el sector central del Tajo Medio. En todas estas regiones la fuerte concentración de esculturas sugiere un intento de demarcación de límites con Galaicos y Astures en el primer caso, con Carpetanos en el segundo y con Oretanos en el último. Pero es muy interesante señalar que otros límites del grupo vettón están marcados de otra forma (Fig. 7). En efecto, hacía el Noreste no existen apenas verracos que dibujen una "frontera" con los grupos Vacceos y en cambio lo que encontramos es una "tierra de nadie" con un vacío poblacional. El contacto y/o relaciones con los Vacceos debió ser diferente y aquí la "frontera" se establece de manera distinta, en negativo a través de una zona desocupada, presuntamente un área transicional entre las tierras ganaderas de Vettones y las agrícolas del Duero Medio de Vacceos. Por último en la "frontera" occidental encontramos, aparentemente, otra situación: existen verracos cuya distribución va marcando una "frontera" difusa que de forma gradual establece los límites con los Lusitanos. El carácter eminentemente ganadero de ambos pueblos y las fuertes relaciones entre ambos que encontramos en las fuentes clásicas, a lo que habría que sumar el hecho de que probablemente los propios Vettones hablaran lusitano, sugieren que aquí la "frontera" es menos marcada.

(3) Por último, sería muy interesante analizar cómo se comportan las cerámicas decoradas a peine (Fig. 5). Las especies a peine de la Segunda Edad del Hierro (Cogotas II) no "pasan" al otro lado de los límites del grupo Vettón en las regiones del Noroeste, "frontera" con Galaicos, del Occidente, "frontera" con Lusitanos, y del Sur, "frontera" con Oretanos. Se puede afirmar que existe una especie de barrera o "frontera" tapón para la circulación y/o producción de esta clase de cerámica. Mientras que hacía el Noreste y el sector oriental las especies con decoración a peine -aunque como hemos visto con técnicas y motivos diferenciadosmantienen una cierta fluidez, que podría denotar afinidades de origen de la clase cerámica o simplemente relaciones y significados afines entre estas regiones y el área vettona. En cualquier caso, parece evidente 


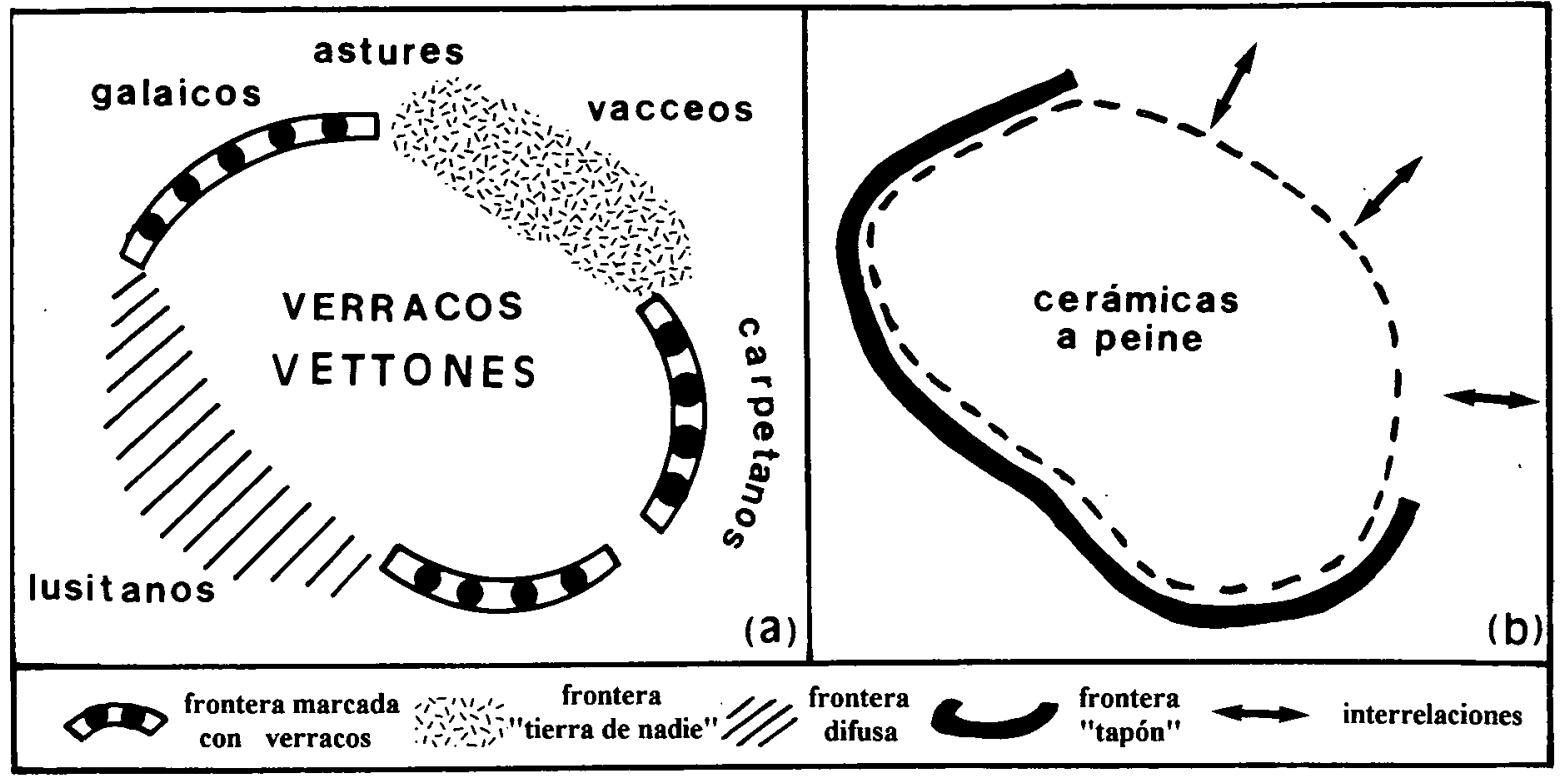

Fig. 7. Esculturas y cerámicas a peine como demarcadores territoriales de la etnia vettona.

que las cerámicas a peine se comportan de distinta manera, en lo que a demarcación territorial se refiere, que las esculturas zoomorfas. Estas últimas son elementos visuales fijos en el paisaje y lo construyen mientras que las cerámicas decoradas son elementos muebles que construyen identidades en las prácticas sociales cotidianas. Hay mucho que indagar en este aspecto de la cerámica y estamos preparando un estudio en esa dirección.

Es seguro que muchas de las cuestiones aquí planteadas no son más que meras conjeturas o suposiciones que no están demostradas, pero aún así pensamos que la construcción de teoría y metodología arqueológica sobre la etnicidad y la cultura material de comunidades prehistóricas es una vía posible y con futuro. Y aunque nos falte esa teoría y esa metodología, sólo el empeño de iniciar la tarea a partir de conjeturas -que tienen ciertamente un valor en el proceso de construcción de conocimiento-nos puede colocar en la dirección correcta para acercarnos al registro arqueológico desde otra perspectiva. 


\section{BIBLIOGRAFÍA}

ABASCAL, J.M. (1995): "Las inscripciones latinas de Santa Lucía del Trampal (Alcuéscar, Cáceres) y el culto de Ataecina en Hispania", Archivo Español de Arqueología 68: 31-105.

ALTARES, J. y MISIEGO, J.C. (1992): "La cerámica con decoración a peine de la necrópolis de Carratiermes (Montejo de Tiermes, Soria)", II Symposium de Arqueología Soriana, I: 543-558. Soria.

ÁLVAREZ-SANCHÍS, J.R. (1994): "Zoomorphic Iron Age sculpture in western Iberia: symbols of social and cultural identity?", Proceedings of the Prehistoric Society 60: 403-416.

(1998): "Verracos vettones y espacios sociales: Arqueología del Paisaje en la Edad del Hierro", en

F. Burillo (Coord.), Arqueología del Paisaje. Arqueología Espacial 19-20: 609-631. Teruel.

(1999): Los Vettones. Bibliotheca Archaeologica Hispana, 1. Real Academia de la Historia. Madrid.

— y RUIZ ZAPATERO, G. (1999): "Paisajes de la Edad del Hierro: Pastos, ganado y esculturas en el valle de Amblés (Ávila)”, en R. Balbín y P. Bueno (eds.), II Congreso de Arqueología Peninsular: 313-323. Zamora.

BANKS, M. (1996): Ethnicity: Anthropological Constructions. Londres, Routledge.

BARBER, E.J.W. (1999): “Colour in Early Cloth and Clothing”, Cambridge Archaeological Journal 9 (1): 117-120.

BARTH, F. ed. (1969): Ethnic Groups and Boundaries: The Social Organization of Culture Difference. Boston, Little Brown.

BARRIO, J. (1988): Las cerámicas de la necrópolis de Las Erijuelas. Cuéllar(Segovia). Diputación Provincial de Segovia.

(1993): "Estratigrafía y desarrollo poblacional en el yacimiento prerromano de la Plaza del Castillo (Cuéllar, Segovia)", en F. Romero, C. Sanz y Z. Escudero (eds.), Arqueología Vaccea. Estudios sobre el mundo prerromano en la Cuenca media del Duero: 173-212. Junta de Castilla y León, Valladolid.

BRAUN, D. P. (1991): "Why Decorate a Pot ? Midwestern Household Pottery, 200 B.C.-A.D. 600", Journal of Anthropological Archaeology 10: 360-397.

— y PLOG, S. (1982): "Evolution of "Tribal" Social Networks: Theory and Prehistoric North American Evidence", American Antiquity 47: 504-525.

BURILLO, F. (1998): Los Celtíberos. Etnias y Estados. Barcelona, Crítica.

CABRE, J. (1932): Excavaciones en Las Cogotas. Cardeñosa (Ávila). II. La Necrópoli. Junta Superior de Excavaciones y Antigüedades, 120. Madrid.

; CABRÉ, Ma.E. y MOLINERO, A. (1950): El Castro y la Necrópolis del Hierro Céltico de Chamartín de La Sierra (Ávila). Acta Arqueológica Hispánica, V. Madrid.

CABRÉ, Ma .E. y CABRÉ, J.A. (1990): "Pinzas ibéricas caladas "tipo Cigarralejo" en la necrópolis de La Osera (Ávila)", Verdolay 2: 77-80.

DAVID, N.; STERNER, J. y GAVUA, K. (1988): "Why Pots Are Decorated", Current Anthropology 29 (3): 365-389.

DELIBES, G. y ROMERO, F. (1992): "El último milenio a.C. en la Cuenca del Duero. Reflexiones sobre la secuencia cultural”, en M. Almagro-Gorbea y G. Ruiz Zapatero (eds.), Paleoetnología de la Península Ibérica. Complutum 2-3: 233-258.

DÍAZ, A. (1976): “La cerámica de la necrópolis celtibérica de Luzaga (Guadalajara) conservada en el Museo Arqueológico Nacional”, Revista de Archivos, Bibliotecas y Museos 79 (2): 397-489.

DÍAZ-ANDREU, M. (1998): "Ethnicity and Iberians: the archaeological crossroads between perception and material culture", European Journal of Archaeology 1 (2): 199-218.

DOLUKHANOV, P. M. (1989): "Cultural and ethnic processes in prehistory as seen through the evidence of archaeology and related disciplines", en S.J. Shennan (ed.) Archaeological Approaches to Cultural Identity: 267-277. Londres, Unwin Hyman. 
DRAGADZE, T. (1980): "The place of "ethnos" theory in Soviet anthropology", en E. Gellner (ed.) Soviet and Western Anthropology: 161-170. Londres, Duckworth.

EICHER, J. B. ed. (1995): Dress and Ethnicity: Change Across Space and Time. Oxford, Berg.

EMBERLING, G. (1997): "Ethnicity in Complex Societies: Archaeological Perspectives", Journal of Archaeological Research 5 (4): 295-344.

ERIKSEN, T. H. (1992): Us and Them in Modern Societies: Ethnicity and Nationalism in Mauritius, Trinidad and Beyond. Londres, Scandinavian University Press.

- (1993): Ethnicity and Nationalism: Anthropological Perspectives. Londres, Pluto Press.

ESPARZA, A. (1986): Los Castros de la Edad del Hierro del Noroeste de Zamora. Instituto de Estudios Zamoranos Florián de Ocampo. Zamora.

FERNÁNDEZ GÓMEZ, F. (1986): Excavaciones Arqueológicas en el Raso de Candeleda (I-II). Institución Gran Duque de Alba. Ávila.

FISHMAN, J. A. (1977): Language, Ethnicity and Intergroup Relations. Londres, Academic Press.

FRIEDRICH, M. (1970): "Design structure and social interaction: Archaeological implications of an ethnographic analysis", American Antiquity 35: 332-343.

GAGE, J. (1999): “Did colours Signify? Simbolism in the Red”, Cambridge Archaeological Journal 9(1): $110-112$.

GARCÍA-BELLIDO, Mํ.P. (1995): "Célticos y Púnicos en la Beturia según los documentos monetales", Celtas y Túrdulos: La Beturia. Cuadernos Emeritenses 9: 256-292. Mérida.

GARCÍA-SOTO, E. y DE LA ROSA, R. (1990): "Aproximación al estudio de las cerámicas con decoración "a peine" en la Meseta Norte", en F. Burillo (coord.), Necrópolis Celtibéricas. II Simposio sobre los Celtíberos: 305-310. Institución Fernando el Católico, Zaragoza.

GONZÁLEZ-CONDE, Mª.P. (1986): "Elementos para una delimitación entre Vettones y Carpetanos en la provincia de Toledo", Lucentum V: 87-93.

GONZÁLEZ CORDERO, A. y QUIJADA, D. (1991): Los orígenes del Campo Arañuelo y la Jara cacereña y su integración en la prehistoria regional. Navalmoral de la Mata.

GONZÁLEZ-TABLAS, F.J. (1990): "La necrópolis de "Los Castillejos" de Sanchorreja. Su contexto histórico. Acta Salmanticensia 69. Salamanca.

GRAVES-BROWN, P.; JONES, S. y GAMBLE, C. Eds. (1996): Cultural Identity and Archaeology. Londres, Routledge.

HALL, J. (1997): Ethnic Identity in Greek Antiquity. Cambridge, C.U.P.

HALL, J.M. (1998): "Discourse and Praxis: Ethnicity and Culture in Ancient Greece", Cambridge Archaeological Journal 8 (2): 266-269.

HÄRDTH, B. (1985-86): Ceramic Decoration and Social Organization. Regional variations seen in material from South Swedish Passage-Graves. Lund, Scripta Minora, 1.

HERNÁNDEZ, F. (1981): "Cerámica con decoración "a peine"”, Trabajos de Prehistoria 38: 317-326.

HERNÁNDEZ SOBRINO, Ma . del R. (1995): "La integración del territorio oriental de los vettones en el marco administrativo-provincial romano", Hispania Antiqua XIX: 77-93.

HODDER, I. (1982): Symbols in action. Cambridge University Press. New Studies in Archaeology. Cambridge.

HOLE, F. (1984): "Analysis of structure and design in prehistoric ceramics", World Archaeology 15 (3): 326-347.

JAMES, S. (1999): The Atlantic Celts. Londres, British Museum Press.

JONES, S. (1997): The Archaeology of Ethnicity: Constructing Identities in the Past and the Present. Londres, Routledge.

— (1998): "Ethnic Identity as Discursive Strategy: the Case of the Ancient Greeks", Cambridge Archaeological Journal 8 (2): 271-273. 
JUST, R. (1998): “The Historicity of Ethnicity", Cambridge Archaeological Journal 8 (2): 277-279.

KNAPP, R.C. (1992): Latin Inscriptions from Central Spain. University of California Press. Berkeley \& Los Angeles, California.

LORENZ, H. (1985): "Regional organization in the western Early La Tène province: the Marne-Mosel and Rhine-Danube groups", en T.C. Champion y J.V.S. Megaw (eds.), Settlement and Society. Aspects of West European Prehistory in the first Millenium B.C.: 109-122. University of Leicester.

LORRIO, A. (1990): "La Mercadera (Soria): organización social y distribución de la riqueza en una necrópolis celtibérica", en F. Burillo (coord.), Necrópolis Celtibéricas. II Simposio sobre los Celtíberos: 39-50. Institución Fernando el Católico. Zaragoza.

MARTÍN VALLS, R. (1985): "Segunda Edad del Hierro. Las culturas prerromanas”, en J. Valdeón (ed.), Historia de Castilla y León. I. La Prehistoria del Valle del Duero: 104-131. Ámbito, Valladolid.

_ (1986-87): “La Segunda Edad del Hierro: consideraciones sobre su periodización", Zephyrus XXXIXXL: 59-86.

— y PÉREZ HERRERO, E. (1976): “Las esculturas zoomorfas de Martiherrero (Ávila)”, Boletín del Seminario de Arte y Arqueología XLII: 67-88.

MAYOR, A. (1991-92): "La durée de vie des céramiques africaines: un essai de compréhension des mecanismes", Bulletin du Centre Genevois d'Anthropologie 3: 47-70.

MORRIS, Y. (1998): "Words and Things", Cambridge Archaeological Journal 8 (2): 269-270.

OLSEN, B. y KOBYLINSKI, Z. (1991): "Ethnicity in anthropological and archaeological research: a Norwegian-Polish perspective", Archaeologia Polona 29: 5-27.

PLOG, S. (1978): "Social analysis and stilistic similarity: a reanalysis", en M.B. Schiffer (ed.) Advances in Archaeological Method and Theory 1 : 144-182. Nueva York, Academic Press. (1980): Stylistic variation in prehistoric ceramics. Nueva York, Cambridge University Press.

RAMÓN y FERNÁNDEZ OXEA, J. (1950): "Nuevas esculturas zoomorfas prehistóricas en Extremadura", Ampurias XII: 55-78.

RENFREW, C. (1987): Archaeology and Language. Londres, Jonathan Cape.

- (1993): The Roots of Ethnicity: Archaeology, Genetics and the Origins of Europe. Roma, Unione Internazionale degli Instituti di Archeologis, Storia e Storia dell’Arte in Roma. (1998): "From Here to Ethnicity", Cambridge Archaeological Journal 8 (2): 275-277.

RODRÍGUEZ, J. (1879): La Vettonia. Imprenta de Fortanet, Editor. Madrid.

RODRÍGUEZ ALMEIDA, E. (1981): Ávila Romana. Caja General de Ahorros y Monte de Piedad. Ávila.

ROLDÁN HERVAS, J.M. (1968-69): "Fuentes antiguas para el estudio de los Vettones", Zephyrus XIX-XX: 73-106.

ROWLETT, R. M. (1989): “Detecting political units in archaeology - an Iron Age example", en S.J. Shennan (ed.) Archaeological Approaches to Cultural Identity: 219-230. Londres, Unwin Hyman.

RUIZ, A. y MOLINOS, M. (1993): Los Iberos. Análisis arqueológico de un proceso histórico. Barcelona, Crítica.

RUIZ ZAPATERO, G. y ÁLVAREZ-SANCHÍS, J.R. (1995): "Las Cogotas: Oppida and the Roots of Urbanism in the Spanish Meseta", en B. Cunliffe y S.J. Keay (eds.), Social Complexity and the Development of Towns in Iberia: from the Copper Age to the second century AD. Proceedings of the British Academy 86: 209-236. London.

_- (1999): "Ulaca: La "Pompeya" vettona", Revista de Arqueología 216: 36-47.

SANZ MÍNGUEZ. C. (1993): "Uso del espacio en la necrópolis celtibérica de Las Ruedas, Padilla de Duero (Valladolid): cuatro tumbas para la definición de una estratigrafía horizontal”, en F. Romero, C. Sanz y Z. Escudero (eds.), Arqueología Vaccea. Estudios sobre el mundo prerromano en la Cuenca media del Duero: 371-396. Junta de Castilla y León. Valladolid. 
SAYAS, J.J. y LÓPEZ MELERO, R. (1991): "Vettones", en J.M. Solana (ed.), Las entidades étnicas de la Meseta norte de Hispania en época prerromana. Anejos de Hispania Antiqua: 75-123. Universidad de Valladolid.

SECO, M. y TRECEÑO, F.J. (1993): "La temprana "iberización" de las tierras del sur del Duero a través de la secuencia de "La Mota", Medina del Campo (Valladolid)", en F. Romero, C. Sanz y Z. Escudero (eds.), Arqueología Vaccea. Estudios sobre el mundo prerromano en la Cuenca media del Duero: 133-171. Junta de Castilla y León. Valladolid.

SHENNAN, S. (1989): "Introduction: archaeological approaches to cultural identity", en S.J. Shennan (ed.) Archaeological Approaches to Cultural Identity: 1-32. Londres, Unwin Hyman.

(1991): "Some current issues in the archaeological identification of past peoples", Archaeologia Polona 29: 29-37.

STERNER, J. (1989): "Who is signalling whom? Ceramic style, ethnicity and taphonomy among the Sirak Bulahay", Antiquity 63: 451-459.

TABOADA, J. (1949): "La Cultura de los Verracos en el Noroeste Hispánico", Cuadernos de Estudios Gallegos IV: 5-26.

TOVAR, A. (1985): "La inscripción del Cabeço das Fráguas y la lengua de los lusitanos", Actas del III Coloquio sobre lenguas y culturas paleohispánicas (Lisboa 1980): 227-253. Salamanca.

VAN HEERINGEN, R.M. (1989): “The Iron Age in the Western Netherlands V: Synthesis”, Berichten van de Rijksdienst Voor het Ondheikundig, Bodernonderzoek 39: 157-255.

VEIT,U. (1989): "Ethnic concepts in German Prehistory: A case study on the relationships between cultural identity and archaeological objectivity", en S. Shennan (ed.) Archaeological Approaches to Cultural Identity: 35-56. Londres, Unwin Hyman.

WELLS, P. S. (1998): "Identity and Material Culture in the Later Prehistory of Central Europe", Journal of Archaeological Research 6 (3): 239-298.

(2001): Beyond Celts, Germans and Scythians: Archaeology and Identity in Iron Age Europe. Londres, Duckworth. 